\title{
CARACTERIZAÇÃO MOLECULAR DE ACESSOS DE MELÃO COLETADOS NO NORDESTE BRASILEIRO ${ }^{1}$
}

\author{
ANA CAROLINA DE ASSIS DANTAS², GLAUBER HENRIQUE DE SOUSA NUNES ${ }^{3}$, \\ IONÁ SANTOS ARAÚJO ${ }^{4}$, LEIDIANE BEZERRA ALBUQUERQUE 5
}

RESUMO - O meloeiro está distribuído em todo o mundo, e é a espécie que possui a maior variabilidade fenotípica do gênero, observada principalmente em seus frutos. Existe grande variabilidade que consiste em importante fonte de germoplasma para programas de melhoramento. Portanto, o conhecimento da variabilidade genética de espécies vegetais e como ela se distribui, proporciona o uso racional e sustentável dos recursos genéticos. O objetivo do presente trabalho foi realizar a caracterização molecular de acessos de meloeiro coletados no Nordeste brasileiro. Foram avaliados 40 acessos e três cultivares comerciais. A caracterização molecular foi realizada com marcadores RAPD, utilizando 18 primers, os quais geraram 139 marcas polimórficas. Com os dados de similaridade genética, foram obtidos 32 grupos, e a similaridade entre os genótipos variou de 34 a 100\%. Verificou-se que os marcadores RAPD foram satisfatórios em permitir a detecção de polimorfismo entre os genótipos avaliados. Os métodos de agrupamento de Tocher e o hierárquico concordaram parcialmente. O banco de germoplasma de meloeiro da UFERSA possui alta variabilidade genética entre os acessos.

Termos para indexação: Cucumis melo, germoplasma, marcador RAPD.

\section{MOLECULAR CHARACTERIZATION OF MELON ACCESSES COLLECTED IN THE BRAZILIAN NORTHEAST}

\begin{abstract}
The melon plant is distributed all over the world, and it is the species that possesses the largest phenotypic variability of the genus, observed mainly in their fruits. There is a great variability that consists of important germoplasm source for improvement programs. Therefore, the knowledge of the genetic variability of vegetable species and how it is distributed provides the rational and maintainable use of the genetic resources. The objective of the present study it was to characterize 40 accesses and three commercial cultivars of melon collected in the Brazilian Northeast by RAPD markers. Forty of the 18 RAPD primers analyzed, of which generated 139 polymorphic markers. Through of the genetic similarity data were obtained 32 groups and the similarity among the genotypes varied from 36 to $100 \%$. It was verified that the RAPD markers were satisfactory to detect the polymorphism among the genotypes analyzed. The Tocher and hierarchical grouping methods agreed partially. The germoplasm bank of UFERSA presents high genetic variability among the accesses.
\end{abstract}

Index terms: Cucumis melo, germoplasm, RAPD marker.

\footnotetext{
${ }^{1}$ (Trabalho 135-11). Recebido em: 20-04-2011. Aceito para publicação em: 29-02-2012.

${ }^{2}$ Doutoranda em Fitotecnia pela Universidade Federal Rural do Semi-Árido, Mossoró-RN, Brasil. E-mail: anacaroldantas@yahoo.com.br ${ }^{3}$ Prof ${ }^{\circ}$. Associado I, Depto. Ciências Vegetais, Universidade Federal Rural do Semiárido, Mossoró-RN, Brasil. E-mail: glauber@ufersa.edu.br

${ }^{4}$ Prof $f^{a}$. Adjunta II, Depto. Ciências Vegetais, Universidade Federal Rural do Semiárido, Mossoró-RN, Brasil. E-mail: iona@ufersa.edu.br ${ }^{5}$ Mestranda em Fitotecnia pela Universidade Federal Rural do Semiárido, Mossoró-RN, Brasil. E-mail: leidy_albuquerque@hotmail.com
} 


\section{INTRODUÇÃO}

O melão (Cucumis melo L.) é uma hortaliça conhecida e cultivada há vários séculos no mundo todo. Possui grande importância econômica e contribui significantemente para geração de empregos e para economia brasileira, principalmente na região Nordeste. Em 2009, o Nordeste brasileiro foi responsável por $95,8 \%$ da produção nacional de melão, destacando-se os Estados do Rio Grande do Norte (46,6\%), Ceará (35\%), Bahia (10,5\%) e Pernambuco (3,5\%) (IBGE, 2009).

Dentro do gênero Curcubita, a $C$. melo é a espécie mais polimórfica, com variações nos caracteres da planta, folhas, flores e frutos, sendo tal polimorfismo maior em relação às características de seus frutos, por apresentar diferentes cores de polpa, cor de casca, aroma, formas e tamanhos (STAUB et al., 2002). O meloeiro apresenta excelente adaptação às condições edafoclimáticas predominantes na região Nordeste do Brasil, onde as condições de solo e clima garantem o crescimento e o desenvolvimento adequado das plantas. Essa região dispõe de várias espécies de cucurbitáceas introduzidas há muitos anos por escravos e imigrantes. Essas espécies são cultivadas até hoje na agricultura de sequeiro e subsistência, em pequenos estabelecimentos agrícolas, tendo originado diversas cultivares tradicionais ou cultivares crioulas ou também denominadas de landraces (QUEROL, 1993).

Para evitar a perda desse rico banco de alelos, é necessária a coleta do material e sua caracterização. A caracterização é uma atividade primordial para geração de conhecimentos sobre o germoplasma conservado em bancos ou coleções, por permitir melhor manejo dos acessos e por fornecer subsídios para a conservação e preservação, bem como para a utilização em programas de melhoramento. No Brasil, a conservação de germoplasma de melão é realizada pela Embrapa e por algumas universidades públicas.

O conhecimento da variabilidade genética de espécies vegetais e de como ela se distribui, proporciona o uso racional e sustentável dos recursos genéticos selvagens ou domesticados. Uma das ferramentas para se obter esse conhecimento é a caracterização molecular. As técnicas que utilizam marcadores moleculares estão disponíveis e constituem uma das ferramentas mais interessantes para se caracterizar acessos de um banco de germoplasma. Dentre as classes de marcadores, o RAPD (Random Amplified Polymorphic DNA) tem-se destacado por ser prático, rápido, de baixo custo e por identificar alto número de lócus polimórficos nos segmentos de DNA. A caracterização molecular de acessos de germoplasma de meloeiro de várias partes do mundo, pelo uso do marcador RAPD, tem sido tema de muitos artigos publicados na literatura internacional (MLIKI et al., 2001; STAUB et al., 2004; LUAN et al., 2008). No Brasil, ainda há carência de informações moleculares nos acessos coletados em pequenas propriedades, sendo necessários esforços para se obter o referido conhecimento.

Diante dessas considerações, o objetivo do presente trabalho foi estudar a variabilidade genética de acessos de meloeiro coletados na região Nordeste do Brasil por características moleculares com marcadores RAPD.

\section{MATERIAL E MÉTODOS}

As análises moleculares com marcadores RAPD foram realizadas no Laboratório de Fitopatologia do Departamento de Ciências Vegetais da Universidade Federal Rural do Semiárido - UFERSA, durante o ano de 2010. Foram avaliados 43 acessos (Tabela 1), coletados no Nordeste do Brasil, presente no Banco Ativo Germoplasma da UFERSA, Mossoró-RN. São eles: A-01, A-02, A-03, A-04, A-05, A-06, A-23, A-30, A-37, coletados no Rio Grande do Norte; A-07, A-08, A-09, A-45, coletados no Ceará; A-11, A-12, A-36, A-44, coletados em Pernambuco; A-13, A-14, A-31, coletados na Paraíba; A-15, A-24, A-25, coletados em Alagoas; A-16, A-17, A-32, A-34, A-39, A-42, coletados na Bahia; A-18, A-19, A-41, coletados no Piauí; A-22, A-27, A-28, A-29, A-33, A-43, coletados no Maranhão; A-26, A-35 coletados em Sergipe e os híbridos: 'Natal' da empresa Syngenta-Rogers; 'Amaral' e 'Mandacaru', da empresa Rijk Zwaan.

As sementes dos acessos/cultivares foram semeadas em bandejas de poliestireno expandido, com 128 células, compostas do substrato comercial Plantmax ${ }^{\circledR}$, sendo o transplantio realizado quando as mudas estavam com um par de folhas definitivas. O DNA de cada um dos genótipos foi extraído a partir do protocolo desenvolvido por Doyle e Doyle (1990), com modificações. Vinte primers decâmeros RAPD (Tabela 2) foram utilizados para amplificar o DNA de 43 acessos de melão. As reações de amplificação foram feitas em um volume total de $20 \mu \mathrm{L}$, contendo $10 \mathrm{mM}(\mathrm{pH} \mathrm{8,3)} \mathrm{de} \mathrm{Tris-HCl,} 50 \mathrm{mM}$ de $\mathrm{KCl}, 2,5$ $\mathrm{mM}$ de $\mathrm{MgCl}_{2}, 200 \mathrm{uM}$ de cada dNTP, $5 \mu \mathrm{M}$ de cada um dos diferentes primers RAPD, 1 U de Taq DNA polimerase e, aproximadamente, $10 \mathrm{ng}$ de DNA. As amplificações foram realizadas em termociclador (Axygen Axygene), de acordo com o seguinte programa: $94^{\circ} \mathrm{C}$ por $5 \mathrm{~min}+40$ ciclos de $94^{\circ} \mathrm{C}$ por 30 
seg, $35^{\circ} \mathrm{C}$ por $1 \mathrm{~min}, 72^{\circ} \mathrm{C}$ por $1 \mathrm{~min}$, extensão final de $72^{\circ} \mathrm{C}$ por 7 min e redução a $15^{\circ} \mathrm{C}$. Os produtos de PCR foram separados em gel de agarose a 1,0\%, corado com brometo de etídio e fotografados sob luz ultravioleta. Os produtos das amplificações foram computados como ausência do alelo (0) e presença do alelo (1).

A dissimilaridade entre os acessos/cultivares foi calculada pelo coeficiente de dissimilaridade de Jaccard (SOKAL; ROHLF, 1962). Para o cálculo da dissimilaridade, foi realizado utilizando o programa GENES (CRUZ, 2006), que gerou as matrizes de distância genética; a partir das matrizes, foram gerados os agrupamentos pelo método de Tocher. Também a partir dessas matrizes, com o auxílio do programa STATISTICA (STATISTICA, 2002), foram gerados agrupamentos pelo método da média aritmética não ponderada (UPGMA), na forma de dendogramas. A eficiência do agrupamento foi feita pela estimativa da correlação cofenética e grau de distorção, conforme descrição de Cruz (2008).

\section{RESULTADOS E DISCUSSÃO}

Dos 20 primers utilizados, apenas dois (OPA-07, OPE-15) não apresentaram bom padrão de amplificação, sendo assim retirados das análises. De acordo com os dados gerados pela amplificação, foram identificados 144 marcadores RAPD; destes, 139 foram polimórficos e apenas cinco monomórficos. A média de alelos polimórficos foi de 10,28 alelos por primer. $\mathrm{O}$ menor número de alelos foi gerado pelo primer OPO-07, e o maior número de alelos, pelo OPC-13. O primer OPO-07 amplificou quatro alelos polimórficos, enquanto com os primers OPC-13 e OPC-05 foram amplificados 14 e 13 alelos polimórficos, respectivamente. Os fragmentos polimórficos RAPD foram selecionados para análise, de acordo com a intensidade da banda no gel. Exemplo de boa amplificação é mostrado na Figura 1, com o primer OPF-02. Buso et al. (2002), analisando 38 acessos de melão, com emprego de 22 primers, obtiveram 63 alelos polimórficos, com a média de 3 alelos por primer. Stepansky et al. (1999) analisaram 54 acessos de melão, com 14 primers RAPD obtiveram 97 alelos, com $70 \%$ sendo polimórficos, com média de 6,9 alelos por primer. Luan et al. (2008), analisando 68 acessos, com 17 primers RAPD, e obtiveram uma média de alelos por lócus de 1,9. Staub et al. (2004) analisaram 17 acessos de melão, com 24 primers RAPD, e detectaram 65 alelos polimórficos, com média de 2,4 alelos por primer. Todos esses autores citados encontraram nível de polimorfismo menor que o encontrado no presente trabalho.

Os acessos de melão foram agrupados em 13 grupos, conforme o método de Tocher, a partir da matriz de dissimilaridade gerada com as marcas de RAPD (Tabela 3). O primeiro grupo foi formado pelos acessos A-11, A-12, A-43, 'Natal', A-14, A-13, A-2, A-5, A-3, A-7, 'Mandacaru', 'Amaral', A-6, A-4, A-24, A-32, A-23, A-42, A-27, A-15, A-16, A-39 e A-41; e o segundo grupo pelos acessos A-19, A-22, A-29, A-30, A-31. Nestes dois grupos, como era esperado, foi alocado o maior número de acessos. Os demais acessos foram divididos em grupos formados por dois acessos ou apenas por um acesso.

A análise do dendograma construído pelo método UPGMA (Figura 2) permitiu verificar a formação de 32 grupos, quando se considerou um ponto de corte com $50 \%$ de dissimilaridade. A menor variação encontrada foi de $34 \%$ de dissimilaridade entre os acessos A-11 e A-12 e a maior foi de $100 \%$ entre o acesso A-18 e os demais. O grupo 1 foi formado pelo acesso A-1, o grupo 2 pelo A-4, o grupo 3 pelo A-44, o grupo 4 apresenta dois acessos, o A-2 e o A-3. No grupo 5, foram alocados os três híbridos avaliados. O agrupamento dos híbridos em um mesmo grupo era esperado em razão de serem materiais melhorados com frutos de excelente qualidade e uniformes quanto ao tamanho, cor de epicarpo e mesocarpo, bem como produtividade. A provável justificativa dos híbridos 'Natal'e 'Amaral' é que, por serem da mesma empresa e, muito provavelmente, por apresentarem o mesmo background genético, justificaram perfeitamente sua alocação no mesmo grupo, em todas as situações. O grupo 6 foi formado pelos acessos A-5, A-6, A-7; o grupo 7 foi formado pelos acessos A-11, A-12 e A-43; o grupo 8 foi formado pelos acessos A-13 e A-14; o grupo 9 formado pelos acessos A-23 e A-24; o grupo 10 foi formado pelos acessos A-31 e A-32; o grupo 11 foi formado pelo acesso A- 35; o grupo 12, pelo A-36; o grupo 13, pelos acessos A- 15 e A-16; o grupo 14, pelo acesso A-45; o grupo 15, pelo acesso A- 39; o grupo 16, pelo acesso A-42; o grupo 17, pelo acesso A- 41; o grupo 18, pelo acesso A-28; o grupo 19, pelo acesso A- 33; o grupo 20, pelo acesso A- 34; o grupo 21, pelo acesso A-19; o grupo 22, pelo acesso A- 22; o grupo 23, pelo acesso A-27; o grupo 24, pelo acesso A- 29; o grupo 25, pelo acesso A- 30; o grupo 26, pelo acesso A-9; o grupo 27, pelo acesso A- 37; o grupo 28, pelo acesso A-17; o grupo 29, pelo acesso A- 26; o grupo 30, pelo acesso A- 25; o grupo 31, pelo acesso A-8; o grupo 32, pelo acesso A- 18; nestes, os acessos apresentaram-se de forma isolada. Os únicos acessos que mostraram correlação entre as distâncias físicas com a similaridade genética foram os acessos A-12 e A-13; os demais não apresentaram correlação, e um ponto a ser considerado é a relação da procedência geográfica como indicador de diversidade genética, pois, em muitos casos, a separação geográfica geralmente não resulta em maior distância genética (CRUZ; CARNEIRO, 2003), o que foi constatado, neste trabalho, pela presença de genótipos de diferentes localidades, que compuseram o mesmo grupo ou de mesmas locali- 
dades que compuseram grupos distintos.

A correlação cofenética foi estimada em $0,77 * *$, valor que evidencia a elevada confiabilidade entre a matriz de distâncias original e a matriz gerada pelo agrupamento UPGMA (SOKAL; ROLPH, 1962). A magnitude da distorção indica a eficiência do agrupamento obtido pelo método UPGMA que também indica boa eficiência na técnica de agrupamento utilizada.

O dendograma obtido demonstra coeficientes de dissimilaridade variando de $34 \%$ a $100 \%$. Gontijo et al. (2005) estudaram a variabilidade em 141 linhagens de melão e encontraram coeficientes de similaridade entre $60 \%$ e $90 \%$, usando 17 marcadores RAPD. Luan et al. (2008), também, utilizando 17 primers RAPD em 68 acessos encontraram coeficiente variando entre 50 e $90 \%$. Staub et al. (2004) analisaram 17 acessos de melão da Grécia e obtiveram um coeficiente de similaridade de $13 \%$ a $60 \%$. Buso et al. (2002), analisando 38 acessos de melão, com o emprego de 22 primers obtiveram coeficiente de similaridade de $53 \%$ a $98 \%$, mostrando que esse estudo apresenta grande variabilidade genética, provavelmente porque se utilizaram materiais bem divergentes, pela existência de grande número de acessos de diferentes origens. Os métodos de agrupamento de Tocher e o hierárquico não concordaram quanto aos grupos formados, apenas os acessos A-2, A-3, Natal, Amaral, Mandacaru, A-5, A-7, A-6, A- 11, A-12, A-43, A-13, A-14, A-23, A-24, A-31, A-32, A-15, A-16, que se agruparam no primeiro grupo no método de Tocher, agruparam no método hierárquico, mas não exatamente no mesmo grupo. Os demais acessos formaram grupos isolados no método hierárquico.

O trabalho de pré-melhoramento refere-se às atividades realizadas com o intuito de conhecer o germoplasma disponível antes de introduzi-lo em um programa de melhoramento. Assim sendo, a caracterização molecular realizada no presente trabalho fornece informações adicionais dos acessos coletados no Nordeste brasileiro e demonstra todo o potencial do uso de marcadores como ferramenta valiosa no melhoramento. As referidas informações, associadas a outras, auxiliarão em futuras tomadas de decisão, visando ao melhor uso da variabilidade genética disponível no programa de melhoramento ora realizado no semiárido brasileiro.

TABELA 1 - Local de coleta dos acessos de melão do Banco de Germoplasma da UFERSA utilizados no presente trabalho. Mossoró-RN, UFERSA, 2010.

\begin{tabular}{|c|c|c|c|}
\hline Acesso & Local de coleta & Acesso & Local de coleta \\
\hline A-1 & Mossoró - RN & A-24 & Arapiraca - AL \\
\hline A-2 & Mossoró - RN & A-25 & Coruripe - AL \\
\hline A-3 & Baraúna - RN & A-26 & Lagarto - SE \\
\hline A-4 & Baraúna - RN & A-27 & São Luís - MA \\
\hline A-5 & Baraúna - RN & A-28 & São João dos Patos - MA \\
\hline A-6 & Assu - RN & A-29 & Paraibano - MA \\
\hline A-7 & Quixeré - CE & A-30 & São José do Mipibu - RN \\
\hline A-8 & Aracati - CE & A-31 & Areia - PB \\
\hline A-9 & Quixeré - CE & A-32 & Itabuna - BA \\
\hline A-11 & Petrolina - PE & A-33 & São Luís - MA \\
\hline A-12 & Petrolina - PE & A-34 & Juazeiro - BA \\
\hline A-13 & Patos - PB & A-35 & Muribeca - SE \\
\hline A-14 & Sousa - PB & A-36 & Jaboatão - PE \\
\hline A-15 & Arapiraca - AL & A-37 & Areia Branca - RN \\
\hline A-16 & Juazeiro - BA & A-39 & Irecê - BA \\
\hline A-17 & Barra do Mendes - BA & A-41 & Paulistana - PI \\
\hline A-18 & Picos - PI & A-42 & Brumado - BA \\
\hline A-19 & Parnaíba - PI & A-43 & Itapecuru - MA \\
\hline A-22 & São Luís - MA & A-44 & Serra Talhada - PE \\
\hline A-23 & Ipanguassu - RN & A-45 & Messejana - CE \\
\hline
\end{tabular}


TABELA 2 - Primers decâmeros RAPD utilizados para amplificar o DNA de acessos de meloeiro coletados no Nordeste brasileiro. Mossoró-RN, UFERSA, 2010.

\begin{tabular}{|cccc|}
\hline Primers & Sequência & Primers & Sequência \\
\hline OPA-03 & 5' AGTCAGCCAC 3' & OPE-15 & 5' ACGCACAACC 3' \\
OPA-04 & 5' AATCGGGCTG 3' & OPF-02 & 5' GAGGATCCCT 3' \\
OPA-07 & 5' GAAACGGGTG 3' & OPF-16 & 5' GGAGTACTGG 3' \\
OPA-13 & 5' CAGCACCCAC 3' & OPO-02 & 5' ACGTAGCGTC 3' \\
OPB-14 & 5' TCCGCTCTGG 3' & OPO-03 & 5' CTGTTGCTAC 3' \\
OPC-05 & 5' GATGACCGCC 3' & OPO-04 & 5' AAGTCCGCTC 3' \\
OPC-13 & 5' AAGCCTCGTC 3' & OPO-06 & 5' CCACGGGAAG 3' \\
OPD-08 & 5' GTGTGCCCCA 3' & OPO-07 & 5' CAGCACTGAC 3' \\
OPE-05 & 5' TCAGGGAGGT 3' & OPO-10 & 5' TCAGAGCGCC 3' \\
OPE-14 & 5' TGCGGCTGAG 3' & OPO-15 & 5' TGGCGTCCTT 3' \\
\hline
\end{tabular}

TABELA 3 - Grupos de acessos formados pelo critério de Tocher a partir das distâncias generalizadas de Mahalanobis a partir dos dados de RAPD. Mossoró-RN, UFERSA, 2010

\begin{tabular}{|c|c|}
\hline Grupo & Acesso \\
\hline & A-11 A-12 A-43 'Natal' A-14 A-13 A-2 A-5 A-3 A-7 'Mandacaru' 'Amaral' A-6 \\
\hline 1 & A-4 A-24 A-32 A-23 A-42 A-27 A-15 A-16 A-39 A-41 \\
\hline II & A-19 A-22 A-29 A-30 A-31 \\
\hline III & A-33 A-34 \\
\hline IV & A-35 A-36 \\
\hline $\mathrm{V}$ & A-17 A-26 \\
\hline VI & A-9 A-37 \\
\hline VII & A-44 \\
\hline VIII & A-28 \\
\hline IX & A-45 \\
\hline $\mathrm{X}$ & A-25 \\
\hline XI & A-1 \\
\hline XII & A-8 \\
\hline XIII & A-18 \\
\hline
\end{tabular}

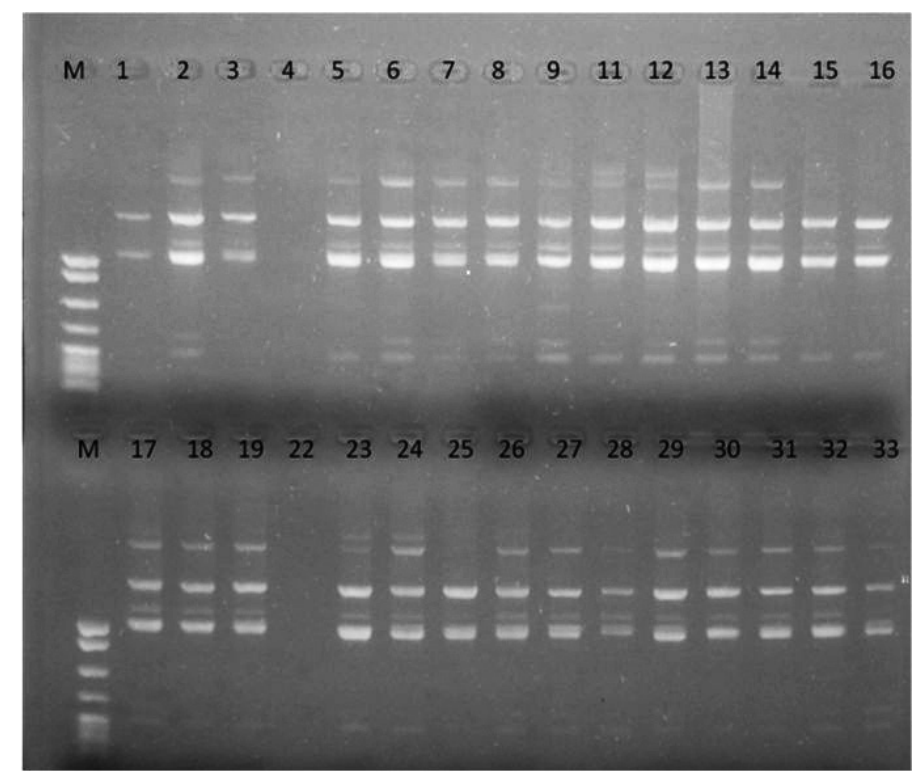

FIGURA 1 - Gel de agarose 1,5\%, contendo fragmentos de DNA amplificados com o marcador RAPD OPF-02, a partir do DNA de alguns acessos de meloeiro. As canaletas 1 e 17 apresentam o padrão do marcador de peso molecular de 100 pares de base. As canaletas 2 a 16 e 18 a 36 representam amostras de diferentes acessos de melão. Mossoró-RN, UFERSA, 2010. 


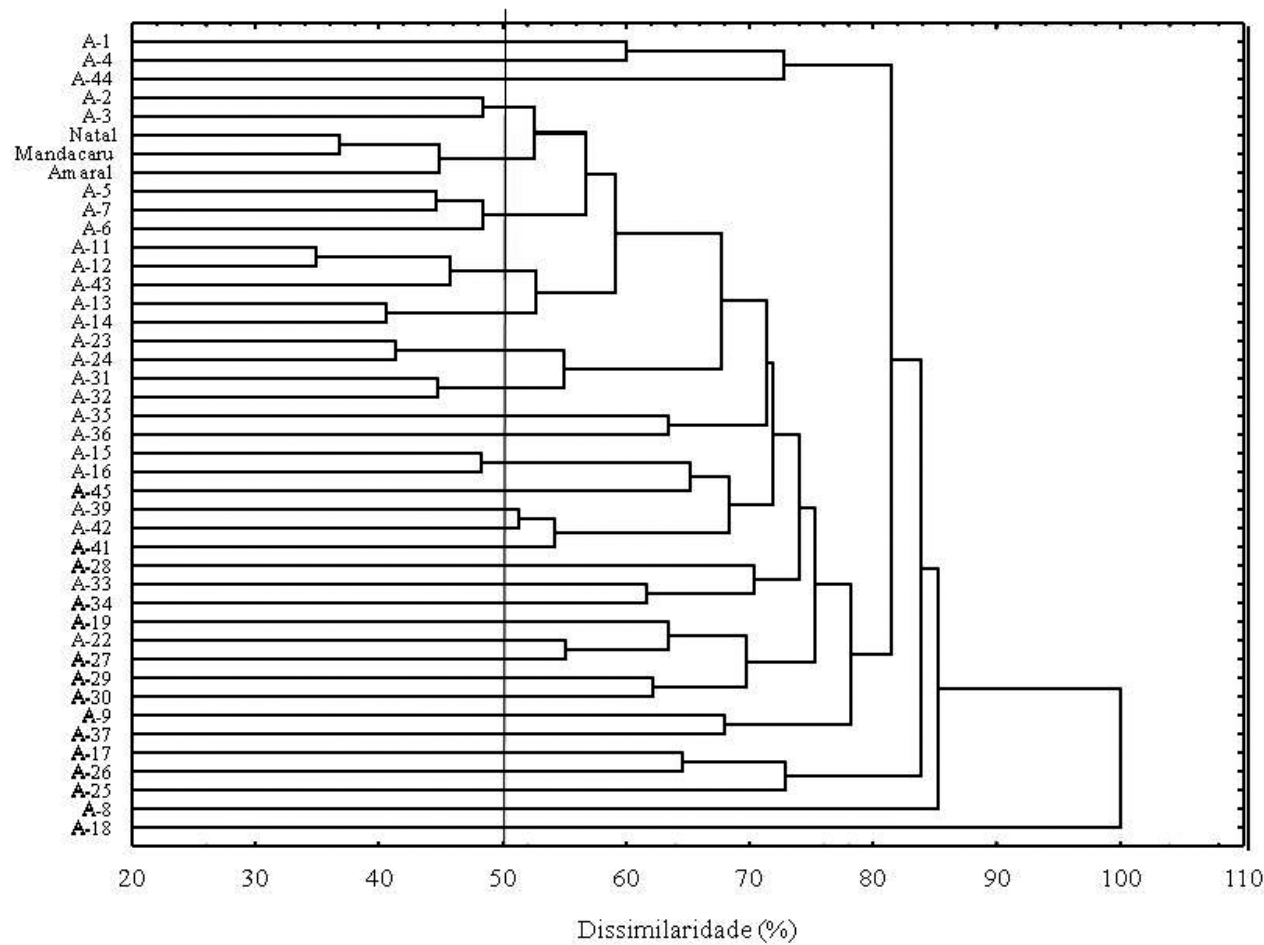

FIGURA 2 - Análise de agrupamento dos 43 genótipos de melão por meio de marcador RAPD, obtida pelo método de agrupamento UPGMA, utilizando a distância de Mahalanobis. Mossoró-RN, UFERSA, 2010. (Correlação cofenética $=0,77^{* *}$; Distorção $\left.=11,34\right)^{* *}$ : significativo $p<0,01$ pelo teste de Mantel.

\section{CONCLUSÕES}

1-Os marcadores RAPD são satisfatórios em permitir a detecção de polimorfismo entre os acessos e cultivares avaliados.

2-Os métodos de agrupamento de Tocher e o hierárquico UPGMA concordam parcialmente nas caracterizações moleculares.

3-Existe alta variabilidade genética entre os acessos do banco de germoplasma da UFERSA.

\section{REFERÊNCIAS}

BUSO, G. S. C.; TAVARES, H. M. F.; BUSO J. A. Avaliação da variabilidade genética de acessos de melão tipo Cantaloupe utilizando marcadores moleculares RAPD. Brasília: Embrapa Recursos Genéticos e Biotecnologia, 2002. 19p. (Boletim de Pesquisa, 35)
CRUZ, C. D. Programa GENES: estatística experimental e matrizes. Viçosa: UFV, 2006. 285p.

CRUZ, C. D.; CARNEIRO P. C. S. Modelos biométricos aplicados ao melhoramento genético. Viçosa: UFV, 2003. v.2. 585p.

DOYLE, I. J.; DOYLE, J. L. Isolation of plant from fresh tissue. Focus, Rockville, v.12, p.13-15, 1990.

GONTIJO, S. L. ; PAIVA, W. P. ; AMORIM, J. C. ; AMARAL, Z . P. de S. ; OLIVEIRA, V. R. ; BUSO, J. A.; BUSO, G. S. C. Análise da variabilidade genética de diferentes linhagens de melão utilizando marcadores moleculares. Horticultura Brasileira, Brasília, v. 23, n. 2, p. 368, 2005.

IBGE- Instituto Brasileiro de Geografia e Estatística. 2009. Disponível em: <www.ibge.gov.br/>. Acesso em: fev. 2011. 
LUAN, F.; DELANNAY, I.; STAUB, J. E. Chinese melon (Cucumis melo L.) diversity analyses provide strategies for germplasm curation, genetic improvement, and evidentiary support of domestication patterns. Euphytica, Wageningen, v. 164, n. 2, p.445-446, 2008.

MLIKI, A.; STAUB, J. E.; ZHANGYONG, S.; GHORBEL, A. Genetic diversity in melon (Cucumis melo L.): Anevaluation of African germplasm. Genetic Resources and Crop Evolution, Dordrecht, v. 48 , n. 6, p. $587-597,2001$.

QUEROL, D. Recursos genéticos, nosso tesouro esquecido. Rio de Janeiro: ASPTA, 1993. 206 p.

SOKAL, R. R.; ROHLF, F. J. The comparison of dendrograms by objective methods. Taxonomy, Berlin, v.11, n.1, p.30-40, 1962.

STATISTICA, Statistica for Windows v. 6.0: Computer Program Manual. Tulsa: StatSoft, 2002.
STAUB, J. E.; LOPEZ-SESÉ, A. I.; FANOURAKIS, N. Diversity among melon landraces (Cucumis melo L.) from Greece and their genetic relationships with other melon germplasm of diverse origins. Euphytica, Wageningen, v. 136, n.2, p. 151-166, 2004.

STAUB, J. E.; ROBBINS, M. D.; LÓPEZ-SESÉ, A. I. Molecular methodologies for improved genetic diversity assessment in cucumber and melon. In: J. D. Creight, ed., Proceedings XXVI IRC. Horticulture: Art and science for life- Advances in vegetable Breeding. Acta Horticulturae, Wageningen, n. 642, p.41-47, 2002.

STEPANSKY, A.; KOVALSKI, I.; PERL-TREVES, $\mathrm{R}$. Intraspecific classification of melons (Cucumis melo L.) in view of their phenotypic and molecular variation. Plant Systematic Evolution, New York, v.217, n.2, p. 313-332, 1999. 